\title{
Growth and mortality in successive cohorts of fish larvae within an estuarine nursery
}

\author{
R. T. Kneib \\ University of Georgia Marine Institute, Sapelo Island, Georgia 31327, USA
}

\begin{abstract}
The young of many coastal fishes appear on estuarine nursery grounds in a progression of successive cohorts, few of which encounter identical environmental conditions. Using in situ manipulations, I explored the effects of natural environmental variability and use of a nursery habitat by prior cohorts on growth and mortality rates in successive larval cohorts of the mummichog Fundulus heteroclitus, a cyprinodontid fish common in salt marshes along the east coast of North America. Variation in mean daily specific rates of growth $(G=0.027$ to 0.143$)$ and mortality $(Z=0.007$ to 0.118$)$ within and among cohorts was associated with the tidal cycle. Growth rate was positively associated and mortality rate negatively associated with the duration of tidal flooding experienced by groups of fish larvae. Tidal flooding may have affected growth and survival by controlling the renewal rate of prey resources (primarily harpacticoid copepods) in intertidal aquatic microhabitats where the fish larvae are normally found. Overall high survival (up to $90 \%$ after $2 \mathrm{wk}$ ) of larvae in experimental cohorts was attributed to the exclusion of predators from field enclosures. Successive cohorts of larvae were not nutritionally independent and use of the nursery habitat by a prior cohort usually had a negative effect on survival of larvae in the next cohort. These findings challenge the general tenet that fish larvae are not foodlimited in nurseries and suggest how variation in the physical environment can restrict food availability even in a highly productive estuarine habitat. The spawning pattern of $F$. heteroclitus seems to combine features from along a continuum of reproductive strategies exhibited by other marine fishes and may contribute to maintaining a large and stable population in a fluctuating estuarine environment.
\end{abstract}

\section{INTRODUCTION}

Many coastal marine species use shallow estuarine habitats as nurseries (Chao \& Musick 1977. Weinstein 1979, Heck \& Thoman 1984J. If annual recruitment of marine species is determined during early life history stages, as is the general tenet, then identifying the mechanisms controlling growth and survival in estuarine nurseries is crucial for understanding the population dynamics of most coastal species. It is widely believed that estuarine nurseries offer young fishes a measure of protection from predators and a plentiful food supply (Boesch \& Turner 1984), but estuaries are also highly variable environments, defined and strongly influenced by the coastal ocean and upland freshwater drainages that border them. Mechanisms controlling growth and survival of early life history stages in estuaries are difficult to identify because the dominant process may vary between sites and change over time. For example, food limitation and predation may be the proximate causes of most mortality in fish larvae, but the effects of these factors, alone or in combination, can be modified by temperature (Frank \& Leggett 1982), river flows (Crecco \& Savoy 1987, Savoy \& Crecco 1988), small-scale turbulence caused by winds and tide (MacKenzie \& Leggett 1991), or a variety of other factors that vary widely within estuaries.

Given the variable physical characteristics of estuaries, it is not surprising that there is considerable spatial and temporal variation in the use of these areas by the young of different fishes and crustaceans (Livingston et al. 1976, Weinstein 1979, Rogers et al. 1984, Allen \& Barker 1990). Many estuarine species produce discrete, successive cohorts of larvae during spawning seasons that may last for several weeks or months (Lipcius \& Subrahmanyam 1986, Grant \& Olney 1990, Zastrow et al. 1991). The young of species that spawn offshore also may enter estuarine nursery grounds as 
discrete cohorts which result from seasonal reproductive patterns (e.g. McBride \& Conover 1991) or population responses to variation in physical factors that may influence larval transport to the estuaries (Norcross \& Shaw 1984, Boehlert \& Mundy 1988, Shaw et al. 1988, Little \& Epifanio 1991). Settlement onto estuarine nursery grounds can be episodic even in populations that continuously produce planktonic larvae (Bauer 1989). Regardless of the original source of the larvae or the mechanism by which successive cohorts are introduced to estuarine nurseries, the environment experienced by each cohort will likely be different and consequently growth and survival vary among cohorts using the same nursery (e.g. Gamble et al. 1985, Leak \& Houde 1987, McBride \& Conover 1991).

Here I describe the results of a field experiment designed to measure the effects of (1) temporal and spatial variability in the physical environment of an estuarine nursery and (2) use of the nursery habitat by prior cohorts on growth and mortality within successive larval cohorts of the mummichog Fundulus heteroclitus. This cyprinodontid is among the most abundant and productive fish in salt marshes along the eastern coast of North America (Valiela et al. 1977. Meredith \& Lotrich 1979) and several features of its life history make it an excellent subject for in situ field experiments. Mummichogs have a protracted spawning season, during which the intensity of reproductive activity varies on a predictable semi-lunar cycle that produces distinct peaks of activity associated with high-amplitude spring tides (Taylor et al. 1979, Kneib 1986a). Near the southern limit of the species' range, the annual spawning pattern consists of 2 distinct reproductive episodes, each lasting 2.0 to 2.5 mo and separated by a period of ca 1.5 mo (mid-May through June) when there is little reproductive activity and fish replenish energy reserves depleted during the first episode (Kneib 1986a). The relatively large $12 \mathrm{~mm}$ diameter) eggs are deposited at high tide on marsh vegetation and in other protected sites high in the intertidal zone (Able 1984). Although larvae are fully developed in 7 to $8 \mathrm{~d}$ (at $25^{\circ} \mathrm{C}$ ), hatching often is delayed until stimulated by tidal immersion during the series of spring tides following those on which the eggs were spawned (Taylor et al. 1977. DiMichele \& Taylor 1980). The strong influence of the lunar-tidal cycle in synchronizing both spawning and hatching in this species results in the production of multiple, distinct cohorts of larvae at intervals of 12 to $15 \mathrm{~d}$. The principal nursery for this species is the intertidal marsh surface where, at low tide, larvae and small juveniles $(<20 \mathrm{~mm})$ are abundant in high marsh pools and shallow (only $\mathrm{mm}$ deep) puddles of residual tidal water in low-lying areas between clumps of vegetation (Kneib 1984). Natural populations of mummichog larvae are confined to these intertidal aquatic microhabitats except when the marsh is tidally inundated. Given that their movements are constrained in the natural habitat, mummichog larvae can be manipulated in caged plots on the intertidal marsh surface with a minimum likelihood of affecting their natural behavior.

\section{MATERIALS AND METHODS}

Study area. The experiment was conducted at 2 intertidal sites (179 and $197 \mathrm{~cm}$ above mean low water, MLW) in a salt marsh near the upper reaches of the Duplin River, a tidal lagoon on the west side of Sapelo Island, Georgia, USA. Intertidal elevations in the study area were determined from field survey data collected with a transit and stadia rod that was combined with tidal height measurements recorded at 10 min intervals for $2 \mathrm{yr}$. There is little direct freshwater inflow to this marsh and salinity is normally 15 to $29 \%$. The area is regularly inundated by mixed semi-diurnal tides, with a total range of ca $2.5 \mathrm{~m}$. Tidal waters flow through a well-developed system of subtidal and intertidal creek channels. Smooth cordgrass Spartina alterniflora is the most conspicuous vascular plant in the intertidal zone from 98 to $210 \mathrm{~cm}$ above MLW.

Physical environmental factors. An electronic data logger (Model EL-824, Omnidata International, Inc), attached to a Druck pressure transducer and 2 thermistors, recorded the depth of tidal inundation and both air and mud surface temperatures at $10 \mathrm{~min}$ intervals. The monitoring station was located at a site $179 \mathrm{~cm}$ above MLW. The duration of tidal inundation at any site $\geq 179 \mathrm{~cm}$ above MLW was calculated by summing the $10 \mathrm{~min}$ intervals during which the recorded water depth indicated that the site was flooded by at least $1 \mathrm{~cm}$. For example, the low site $(179 \mathrm{~cm}$ above MLW) was inundated if the water depth at the monitoring station was $\geq 1 \mathrm{~cm}$, but the high site $[197 \mathrm{~cm}$ above MLW) was inundated only when the water depth at the monitoring site was $\geq 19 \mathrm{~cm}$. A second data logger, located about $4.5 \mathrm{~km}$ to the south, was attached to a pyranometer (Model LI-200SZ, LI-COR, Inc.) which measured the amount of photosynthetically active radiation at $10 \mathrm{~min}$ intervals; these data were used to derive the mean hours of daylight experienced by different cohorts of larvae in the experiment.

Stocks of larvae. Cohorts of larvae were obtained from eggs spawned in the laboratory by adult Fundulus heteroclitus (50 to $100 \mathrm{~mm}$ total length, TL). Fresh spawning stocks were collected twice monthly during March to August 1990 from a tidal creek adjacent to the University of Georgia Marine Institute. Fish collections were timed to coincide with the semi-monthly 


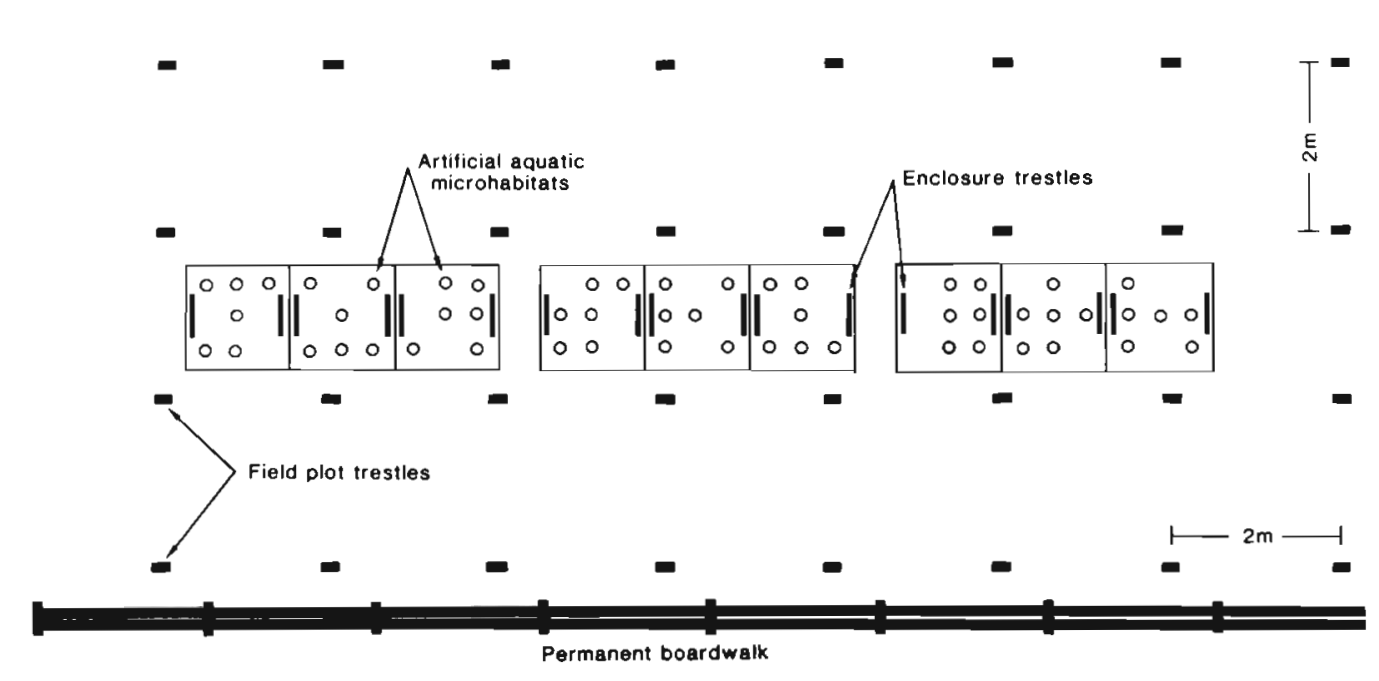

Fig. 1. Diagram of a portion of the $300 \mathrm{~m}^{2}$ field plot at 1 intertidal site showing the spatial arrangement of field enclosures used in the experiment. The emergent marsh vegetation is not depicted. Investigators reached the enclosures by walking on removeable wooden boards ( $2 \mathrm{~m}$ long) that were supported by the field plot trestles. Additional trestles inside the enclosures supported shorter boards (1.1 $\mathrm{m}$ long) that served as platforms from which fish larvae in the artificial aquatic microhabitats (petri dishes) could be sampled without disturbing the marsh surface within the enclosures

peaks in reproductive activity exhibited by the natural populations (Kneib 1986a).

The fish were held in 201 aquaria containing spawning boards, $35 \times 14 \mathrm{~cm}$ wooden blocks with a series of 10 to 12 slots $(0.3 \mathrm{~cm}$ wide $\times 2 \mathrm{~cm}$ deep) cut parallel to the long axis of the block. There were usually 6 aquaria, each containing 12 to 16 adult females and 6 to 8 adult males. Adult fish were fed a daily ration of live grass shrimp Palaemonetes pugio and spawned without artificial inducement, depositing eggs into the slots of the spawning boards at the same time that the natural population spawned in the field. The spawning stock usually produced eggs for 3 to $6 \mathrm{~d}$, after which the spent adults were released. Eggs were collected daily from the aquaria, placed in petri dishes lined with moist paper towels, and incubated at $24^{\circ} \mathrm{C}$ for $2 \mathrm{wk}$. The cultures were cleaned daily by rinsing them with filtered estuarine water and removing any infertile eggs or dead embryos. Under natural conditions, hatching occurs when the embryos are submerged by the tide (DiMichele \& Taylor 1980). Hatching of experimental cohorts was synchronized with the hatching of larvae in the natural population by immersing embryos in estuarine water at the appropriate time.

Field enclosures. Experimental manipulations were conducted within $6 \times 50 \mathrm{~m}$ field plots at both intertidal elevations. Each field plot included a permanent grid of short ( $23 \mathrm{~cm}$ high) wooden trestles placed on $2 \mathrm{~m}$ centers, dividing the plot into seventy-five $2 \times 2 \mathrm{~m}$ squares. The trestles supported removable wooden planks ( $14 \mathrm{~cm}$ wide $\times 2 \mathrm{~m}$ long) that were used to form a temporary boardwalk from which any portion of the grid could be accessed without disturbing the marsh surface. When not in use, the planks were stored in racks located along a permanent boardwalk $(30 \mathrm{~cm}$ wide $\times 45 \mathrm{~cm}$ high) that bordered the long axis of the field plot. Nine enclosures $(1.25 \times 1.25 \times 1 \mathrm{~m}$ high) were constructed within each field plot (Fig. 1). Enclosure walls were of $0.5 \mathrm{~mm}$ mesh polyester screening, with the bottom edge buried 10 to $15 \mathrm{~cm}$ in the marsh substratum; enclosure tops were open. The walls were attached to untreated pine corner posts $(5 \times 5 \times 150 \mathrm{~cm})$ driven $50 \mathrm{~cm}$ into the marsh sediments. Wooden slats $(1 \times 5 \times 100 \mathrm{~cm})$ were attached with stainless steel screws over the mesh at the corner posts to seal the vertical edges of each enclosure. A wooden frame connecting the tops of the corner posts added support and kept the enclosures square. Wooden trestles $15 \mathrm{~cm}$ wide $\times 50 \mathrm{~cm}$ long $\times 20 \mathrm{~cm}$ high) installed along 2 parallel walls inside each enclosure supported removable wooden planks $(5 \times 14 \times 110 \mathrm{~cm})$ that provided a platform from which an investigator could access all points within the enclosure without disturbing the soft marsh substratum within the experimental plot.

Each enclosure also contained 6 artificial aquatic microhabitats which were designed to simulate the natural puddles of residual tidal water in which mummichog larvae are normally found and to provide a standardized method for monitoring fish larvae in the experimental enclosures. Each artificial microhabitat consisted of a glass petri dish $(10 \mathrm{~cm}$ diameter, $1.7 \mathrm{~cm}$ deep) to which 4 small plastic tabs were attached with silicone sealant to the outside bottom surface, and a support collar fashioned from a section of PVC pipe (11.5 cm outside diameter, $10 \mathrm{~cm}$ high). Four holes were drilled at equal intervals around, and 

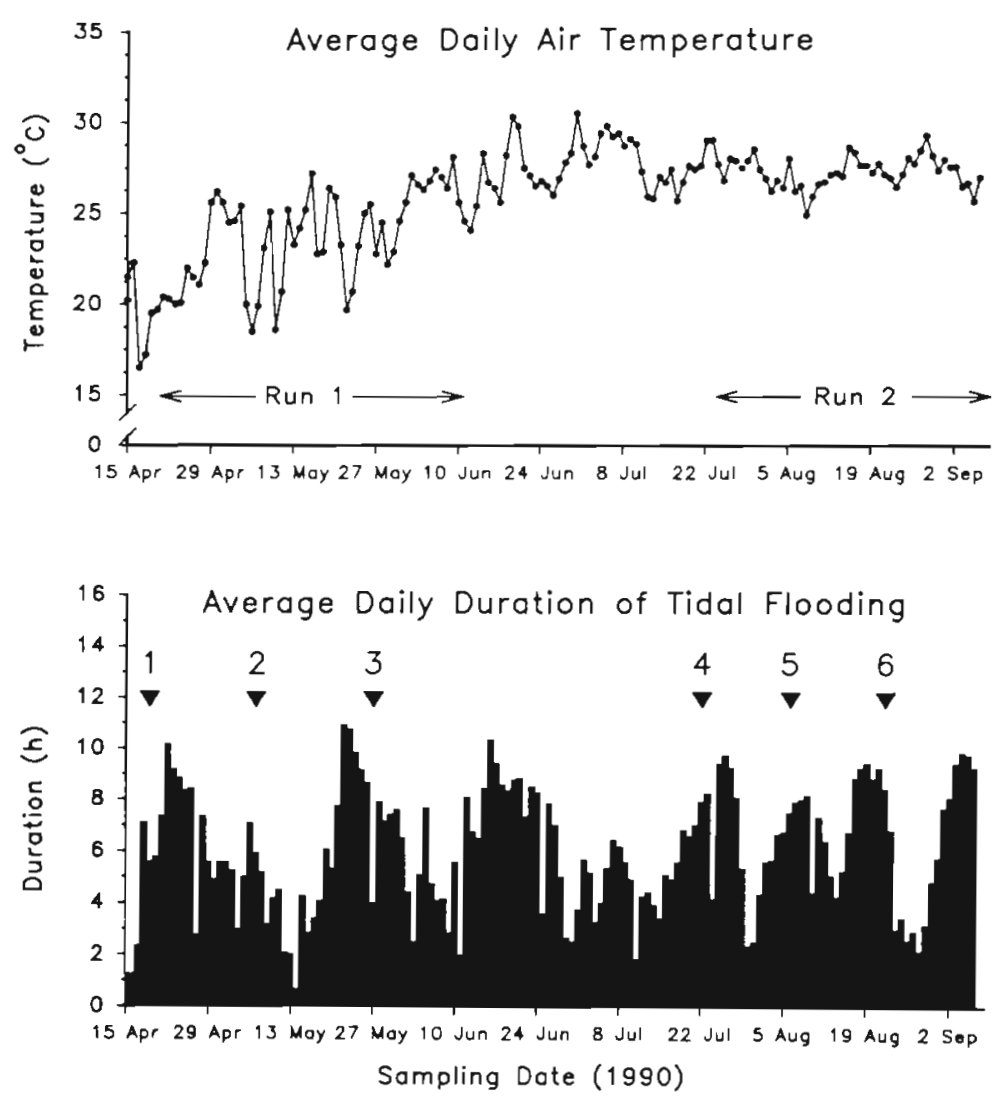

$\nabla$ Introductions of larval cohorts

Fig. 2. Temporal patterns in temperatures (upper) and tidal flooding (lower) at the study site showing the timing of the experimental runs and the introduction of successive larval cohort within each run. Flooding durations are shown for an intertidal elevation midway between the low and high experimental sites

$1.7 \mathrm{~cm}$ below, the top edge of the collar. Two plastic cable ties were passed through the holes so that they formed a cross on the inside of the collar. When the petri dish was placed inside the collar and rotated a quarter turn clockwise, the tabs on the bottom of the dish engaged the cable ties to lock the dish in place; a quarter turn counter-clockwise unlocked the dish. Artificial microhabitats were installed in the enclosures by removing a core $(11.5 \mathrm{~cm}$ diameter, $10 \mathrm{~cm}$ deep) of marsh substratum to create a small pit and then fitting the PVC pipe collar into the pit so that the top edge was just below the marsh surface. When the petri dishes were locked in the collars, they retained tidal water and provided a low-tide aquatic refuge for larval fish within the enclosures. Larvae were sampled at low tide by removing the dishes from the collars and emptying the contents into plastic bags (if the samples were to be retained) or onto $0.5 \mathrm{~mm}$ mesh sieves (if larvae were to be counted and returned to the enclosure).
Experimental design. Fundulus heteroclitus larvae were reared for 13 to $16 \mathrm{~d}$ in field enclosures that had contained either 0,1 or 2 prior cohorts of larvae. Levels of the prior cohort treatment were established by stocking 3 different cohorts of larvae into enclosures at $2 \mathrm{wk}$ intervals (Fig. 2). Three groups of 3 enclosures each were constructed at both intertidal elevations (Fig. 1). At the beginning of the experiment, 100 larvae were stocked into a randomly selected enclosure in each group (a total of 3 stocked enclosures at each elevation); no larvae were added to the remaining enclosures. After ca $2 \mathrm{wk}$, the larvae were removed and replaced with a second group of 100 hatchlings. Larvae from this second cohort also were stocked into another randomly selected enclosure in each group, so that half of the cohort was stocked into enclosures in which there had been no prior cohorts and the other half in enclosures from which a prior cohort had just been removed. After another 2 wk, all of the larvae were removed and a third cohort of hatchlings was stocked into all 18 enclosures. Thus there was a progression in the establishment of the prior cohort treatment levels, with the first cohort containing only the 0-prior cohort treatment, the second including both 0 - and 1 -prior cohort, and the third including 0 -, 1-, and 2-prior cohorts. The experiment was terminated 2 wk after the introduction of the third cohort, and all larvae were removed from the enclosures. At the termination of each successive cohort, the surviving larvae in each enclosure were measured (standard length, SL) to the nearest $0.2 \mathrm{~mm}$, dried to constant weight at $60^{\circ} \mathrm{C}$, and weighed to the nearest $0.01 \mathrm{mg}$

The experiment was run twice to identify any seasonal differences between groups of cohort responses to the field manipulations; each run included 3 cohorts of larvae. The experimental runs (Run 1: 20 April to 11 June 1990; Run 2: 23 July to 6 September 1990) coincided with the 2 major episodes of reproductive activity observed in adult populations of mummichogs on Sapelo Island (Kneib 1986a). Although the same 18 enclosures were used in both runs, the random assignment of prior cohort treatment levels in the second run was independent of that in the first. All enclosures were kept free of fish larvae during the $6 \mathrm{wk}$ interval between runs.

The 3 response variables measured in this study were mean specific growth rate of individuals, mean 
instantaneous per capita mortality rate and mean instantaneous change in cohort biomass. Growth rate of individuals was calculated as:

$$
G=\left[\ln \left(w t_{i}\right)-\ln \left(w t_{0}\right)\right] / t
$$

where $G=$ daily specific growth rate $\left(m g \mathrm{mg}^{-1} \mathrm{~d}^{-1}\right)$; $\mathrm{wt}_{1}=$ dry weight $(\mathrm{mg})$ of a larva at the termination of a cohort on Day $i ; w t_{0}=$ mean dry weight of a larva at the time the cohort was first placed in the field enclosures on Day 0 (Table 1); and $t=$ number of days from initiation to termination of a cohort. The growth rates of all individuals within an enclosure were averaged and considered a single observation or replicate in the data analyses.

Mortality rate was calculated as follows:

$$
Z=\left[\ln \left(\mathrm{n}_{0}\right)-\ln \left(\mathrm{n}_{i}\right)\right] / t
$$

where $Z$ = daily per capita mortality rate in an enclosure $\mathbf{n}_{0}=$ number of larvae placed in the enclosure at the initiation of the cohort (this number was always $100) ; \mathrm{n}_{i}=$ number of larvae surviving at the termination of the cohort on Day $i_{\text {; }}$ and $t$ is as defined for the growth equation.

Change in cohort biomass measured the combined effects of growth and mortality rates on the standing stock biomass of larvae in the enclosures and was calculated as follows:

$$
C=\left[\ln \left(\overline{w t}_{1} n_{i}\right)-\ln \left(w_{0} \mathrm{n}_{0}\right)\right] / t
$$

where $C=$ change in cohort biomass $\left(m g \mathrm{mg}^{-1} \mathrm{~d}^{-1}\right)$, and the other variables are as previously identified.

Statistical analyses. All statistical procedures used in this study are described in Sokal \& Rohlf (1981) and were calculated using Version 4.0 of the statistical package SPSS/PC+ (Norusis 1990). In order to isolate cohort responses to temporal and spatial variation in the nursery environment, an analysis was conducted using only data from larvae reared in enclosures that had not contained prior cohorts. Differences in rates of growth and mortality among the 6 cohorts of larvae were compared in a 2-way analysis of variance (ANOVA) with cohort (6 levels) and intertidal elevation (2 levels) as fixed factor treatments in a $6 \times 2$ factorial design and 3 replicates of each treatment combination. Cohort means were compared at each elevation separately using the conservative Scheffé's procedure ( $\alpha=0.05$ ) because there were significant interactions between cohort and elevation. In comparisons of groups with equal variances (tested by Cochran's $C$ at $\alpha=0.05$ ) but unequal sample sizes, the GT2 procedure $(\alpha=0.05)$ was used to distinguish means that differed significantly.

Sequential establishment of treatment levels $(0-, 1$ and 2-prior cohorts) complicated the analysis of prior cohort treatment effects. Data from Cohorts 1 and 4 (Table 1) were not included in the analysis of prior cohort effects because they were first in the sequence of cohorts for each run and there were no prior cohort enclosures in which to place larvae from these groups (i.e. only the 0 -prior cohort treatment level was possible at the beginning of each run). In the analysis and presentation of the results from this experiment, the 1 and 2-prior cohort treatment levels were combined into a single treatment (prior cohorts added) because a preliminary analysis, including data from only these 2 treatment levels, showed that effects of habitat use were not cumulative (i.e. the effect of 2 prior cohorts was no greater than that of 1 ). This simplified the analysis from a $3 \times 2 \times 2$ ANOVA to a factorial design with 2 levels each of the following 3 fixed-factor treatments: prior cohorts (with or without prior cohort additions), intertidal elevation (high and low) and experimental run (1 and 2). Replication of each treatment combination was unequal; each run and elevation included 6 replicate enclosures in which no prior cohorts had been added and 9 enclosures in which either 1 or 2 prior cohorts had been added for a total of $59(=60-1)$ degrees of freedom (df) for the analysis. Some of the larvae from one replicate of the prior

Table 1. Fundulus heteroclitus. Characteristics of the experimental cohorts of larvae used in the study. Sizes are means \pm 1 SD; $n=40$ for Cohort 1 and $n=10$ for Cohorts 2 to 6

\begin{tabular}{|cccccc|}
\hline Cohort & Spawned & $\begin{array}{c}\text { Dates (1990) } \\
\text { Larvae placed } \\
\text { in field cages }\end{array}$ & $\begin{array}{c}\text { Fish removed } \\
\text { from cages }\end{array}$ & $\begin{array}{c}\text { Size at hatching } \\
\text { Standard } \\
\text { length (mm) }\end{array}$ & $\begin{array}{c}\text { Dry weight } \\
\text { (mg) }\end{array}$ \\
\hline 1 & $25-27 \mathrm{Mar}$ & $20 \mathrm{Apr}$ & $6 \mathrm{May}$ & $6.2 \pm 0.28$ & $0.57 \pm 0.057$ \\
2 & $23-25 \mathrm{Apr}$ & $8 \mathrm{May}$ & $21 \mathrm{May}$ & $5.9 \pm 0.12$ & $0.63 \pm 0.048$ \\
3 & $6-9 \mathrm{May}$ & $28 \mathrm{May}$ & $11 \mathrm{Jun}$ & $6.2 \pm 0.23$ & $0.56 \pm 0.099$ \\
4 & $7-8 \mathrm{Jul}$ & $23 \mathrm{Jul}$ & $5 \mathrm{Aug}$ & $5.9 \pm 0.36$ & $0.46 \pm 0.084$ \\
5 & $24-25 \mathrm{Jul}$ & $7 \mathrm{Aug}$ & $21 \mathrm{Aug}$ & $6.0 \pm 0.16$ & $0.56 \pm 0.049$ \\
6 & $6-8 \mathrm{Aug}$ & $23 \mathrm{Aug}$ & $6 \mathrm{Sep}$ & $5.6 \pm 0.15$ & $0.54 \pm 0.096$ \\
\hline
\end{tabular}


cohort addition treatment level were lost during processing in the laboratory, so this replicate was excluded from the analysis, leaving a total of $58 \mathrm{df}$ for the ANOVA.

\section{RESULTS}

\section{Initial size of larvae}

There were small initial differences among the 6 cohorts of larvae used in the field experiment (Table 1). Most larvae were hatched approximately $2 \mathrm{wk}$ (14 to $16 \mathrm{~d})$ after the eggs were spawned, but hatching of the first and third cohorts was delayed for 7 to $10 \mathrm{~d}$ to avoid complications associated with stocking the larvae into the field enclosures during extreme tidal conditions. In the case of the first cohort, tidal amplitude was much lower than normal at the time the experiment was originally scheduled to begin. Stocking of Cohort 3 was delayed to avoid unusually high tides, which flooded over the tops of the field enclosures. The larvae continued to develop and use their yolk reserves during the hatching delays. Consequently, hatchlings in Cohorts 1 and 3 might be expected to weigh less those in other cohorts. Although a 1-way ANOVA on dry weights at hatching detected a difference (F-test, $\mathrm{p}<0.001$ ) among cohorts, the only significant differences detected in subsequent pairwise comparisons (GT2 procedure, $\alpha=0.05$ ) showed that hatchlings in Cohort 4 weighed less than those in Cohorts 1 and 2. Larvae in cohorts that experienced hatching delays did not weigh significantly less at hatching than those from cohorts hatched on a normal schedule.

\section{Temporal and spatial variability in the intertidal nursery}

Responses of larvae in the 0-prior cohort treatment were used to assess the effects of environmental vari- ability within the intertidal nursery. The analysis detected differences in growth and mortality rates among cohorts, which reflected the effects of factors that varied over time, and between intertidal elevations, which resulted from spatial variability in the nursery environment (Table 2). The interaction between cohort and elevation (Table 2) occurred because differences in growth and mortality rates between intertidal elevations were greater in some cohorts than in others (Table 3). The larvae grew more rapidly at the low than the high intertidal elevation in all but the second cohort. Mortality was lower at the low than at the high intertidal elevation, but differences were statistically significant in only half of the cohorts (Table 3 ).

Initial differences in the mean size of individuals at hatching did not seem to influence cohort responses. For example, there was no difference in growth and mortality rates between Cohorts 1 and 4 (Table 3), even though larvae in Cohort 4 initially weighed less than those in Cohort 1 (Table 1). The observed variation in cohort responses may have reflected either cohort-specific differences in the intrinsic qualities (i.e. bioenergetic characteristics, physiological tolerances, etc.) of larvae or the influence of temporal variability in

Table 2. Fundulus heteroclitus. Summary results of 2-way ANOVAs comparing growth and mortality rates among 6 cohorts of larvae held at high and low intertidal elevations in the absence of habitat use by prior cohorts (only the 0 -prior cohort treatment level is used in the analysis)

\begin{tabular}{|c|c|c|c|}
\hline Source of variation & $\mathrm{df}$ & $\begin{array}{l}\text { Individual growth } \\
\text { rate }\left(\mathrm{mg} \mathrm{mg}^{-1} \mathrm{~d}^{-1}\right)\end{array}$ & $\begin{array}{l}\text { Mortality } \\
\text { rate }\left(Z \mathrm{~d}^{-1}\right)\end{array}$ \\
\hline \multicolumn{4}{|l|}{ Main effects } \\
\hline Cohort & 5 & $\cdots$ & $\cdots$ \\
\hline Intertidal elevation & 1 & $\cdots$ & $\cdots$ \\
\hline \multicolumn{4}{|l|}{ Interaction } \\
\hline Cohort $\times$ Elevation & 5 & $\cdots$ & - \\
\hline Residual & 22 & & \\
\hline$\cdot p \leq 0.05, \cdots p \leq 0.001$ & & & \\
\hline
\end{tabular}

Table 3. Fundulus heteroclitus. Summary of mean specific growth and mortality rates among cohorts of larvae reared in field enclosures at both high and low intertidal elevations. Only data from the 0-prior cohort treatment were used in the analyses. Cohort numbers are the same as in Table 1 and are grouped here into Run 1 and Run 2. Means connected by a common underline did not differ significantly (Scheffé's procedure, experimentwise $\alpha=0.05$ ). Results of $t$-tests comparing means between elevations within a cohort are shown as: $p \leq 0.05, \cdots p \leq 0.01, \cdots p \leq 0.001$, NS: not significant ( $p>0.05$ )

\begin{tabular}{|c|c|c|c|c|c|c|c|c|c|c|c|c|c|}
\hline \multirow{2}{*}{\multicolumn{2}{|c|}{ Elevation }} & \multicolumn{6}{|c|}{ Growth rate $\left(\mathrm{mg} \mathrm{mg}^{-1} \mathrm{~d}^{-1}\right)$} & \multicolumn{6}{|c|}{ Mortality rate $\left(Z \mathrm{~d}^{-1}\right)$} \\
\hline & & \multicolumn{3}{|c|}{ Run 1} & \multicolumn{3}{|c|}{ Run 2} & \multicolumn{3}{|c|}{ Run 1} & \multicolumn{3}{|c|}{ Run 2} \\
\hline & Cohort: & 2 & 3 & 1 & 6 & 4 & 5 & 2 & 3 & 1 & 6 & 4 & 5 \\
\hline High & & $\underline{0.031}$ & 0.041 & 0.087 & 0.073 & 0.098 & 0.111 & $\underline{0.113}$ & 0.118 & 0.050 & 0.052 & 0.033 & 0.018 \\
\hline \multirow[t]{2}{*}{ Low } & & 0.027 & 0.067 & $\underline{0.105}$ & 0.129 & 0.134 & 0.143 & $\underline{0.071}$ & 0.053 & 0.035 & 0.007 & 0.015 & 0.014 \\
\hline & $t$-tests: & NS & $\cdot$ & • & $\cdots$ & $\cdots$ & $\cdots$ & $\cdot$ & * & NS & $\cdots$ & NS & NS \\
\hline
\end{tabular}


environmental conditions. Intrinsic characteristics of the larvae composing each cohort were not measured in this study, but growth and mortality rates among larval cohorts were correlated with variation in some physical environmental factors (Table 4). Although such correlations do not imply a cause and effect relationship, one might expect a correlation if a variable strongly influenced growth and/or mortality. Salinity was not included in the correlation analyses because it was not routinely recorded, but 4 measurements taken during each experimental run had values of 15 to $25 \%$ during Run 1, and 24 to $30 \%$ during Run 2 .

Mean temperatures, hours of daylight and the daily duration of tidal inundation experienced by the cohorts differed significantly ( $t$-tests, $p<0.05$ ) between experimental runs. Broken insulation on a thermistor cable resulted in an erratic and unreliable record of marsh surface temperature. However, the air temperature record (Fig. 2) approximated the variability in the thermal environment experienced by cohorts of fish larvae in each experimental run. Mean ( \pm 1 SD) daily air temperature was lower and more variable during Run $1\left(23.8 \pm 2.64^{\circ} \mathrm{C}, \mathrm{n}=46\right)$ than during Run 2 (27.3 \pm $0.91^{\circ} \mathrm{C}, \mathrm{n}=44$ ), but was not correlated with either growth or mortality (Table 4). The lack of a significant correlation between temperature and cohort responses was due to the relative high growth rate and low mortality rate in Cohort 1 (Table 3), which experienced the lowest mean temperature $\left(22.3 \pm 2.46^{\circ} \mathrm{C}, \mathrm{n}=16\right)$ recorded during the experiment.

Although day length (hours of daylight) was positively correlated with mortality rate (Table 4), it may have been a spurious association because the difference in mean hours of daylight between the 2 experimental runs was relatively small (13.7 \pm $0.33 \mathrm{~h} \mathrm{~d}^{-1}, \mathrm{n}=46$ in Run 1 and $13.1 \pm 0.33 \mathrm{~h} \mathrm{~d}^{-1}, \mathrm{n}=44$ in Run 2) and could not account for the spatial (i.e. intertidal) differences in growth and mortality rates exhibited within a cohort (Table 3 ).

The only measured physical factor that was associated with both temporal and spatial variation in rates of growth and mortality was tidal flooding duration (Table 4, Fig. 3). The mean $( \pm 1$ SD) daily duration of tidal flooding was $6.7 \pm 2.20 \mathrm{~h}(\mathrm{n}=46)$ in Run 1 and $7.7 \pm 2.50 \mathrm{~h}(\mathrm{n}=44)$ in Run 2 at the low intertidal site and was respectively $3.9 \pm 2.08 \mathrm{~h}$ and $5.2 \pm 2.37 \mathrm{~h}$ in Run 1 and 2 at the high intertidal site. Growth rates were positively related and mortality rates negatively related to flooding duration at both intertidal elevations (Fig. 3).

The effect of tidal flooding duration on mortality was evident when approximate survivorship curves, which were derived by periodically monitoring the number of larvae remaining in each enclosure, were compared to the temporal variation in the tidal flooding experienced by each cohort (Fig. 4). Cohorts 2 and 5, in particular, represent responses to the extremes in the tidal flooding regime observed during the experiment. Cohort 2 showed the most rapid decline in survivorship in response to a sustained period of low flooding duration in the middle of Run 1. In contrast, the protracted period of relatively high flooding duration that occurred in the middle of Run 2 was associated with high survivorship within Cohort 5 at both intertidal elevations (Fig. 4). Survivorship in the other cohorts reflected the intermediate tidal flooding conditions that they experienced in the nursery habitat.

Table 4. Fundulus heteroclitus. Pearson product-moment correlation coefficients between the physical environmental factors and mean rates of growth and mortality in groups of larvae reared for 2 wk periods in field enclosures at both intertidal elevations. Only data from the 0-prior cohort treatment level were used ( $n=12)$

\begin{tabular}{|lcc|}
\hline Environmental factor & Growth rate & Mortality rate \\
\hline A.ir temperature $\left({ }^{\circ} \mathrm{C}\right)$ & 0.490 & -0.458 \\
Daylight $\left(\mathrm{h} \mathrm{d}^{-1}\right)$ & -0.654 & $0.683 \cdots$ \\
Tidal flooding $\left(\mathrm{h} \mathrm{d}^{-1}\right)$ & $0.792 \cdots$ & $-0.804 \cdots$ \\
& & \\
1-tailed probabilities: & $\cdots p \leq 0.01, \cdots p \leq 0.001$ \\
\hline
\end{tabular}

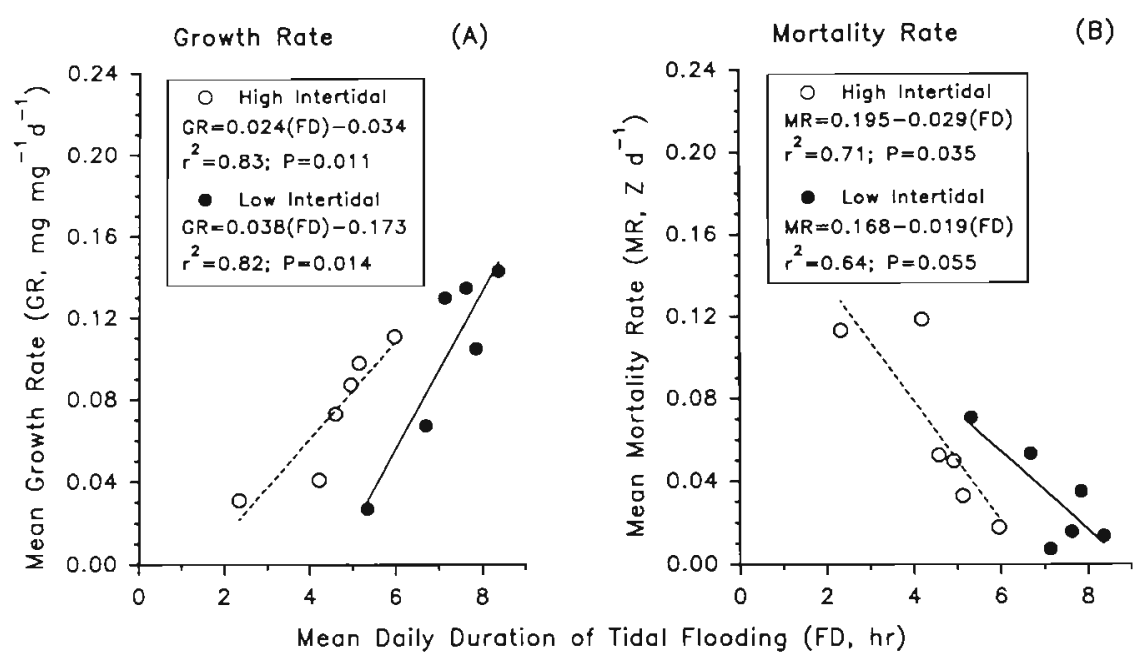

Fig. 3. Fundulus heteroclitus. Relationship between variation in tidal flooding duration at each intertidal elevation and rates of (A) growth and (B) mortality in cohorts of larvae from the 0 -prior cohort treatment. Data from both experimental runs are included 

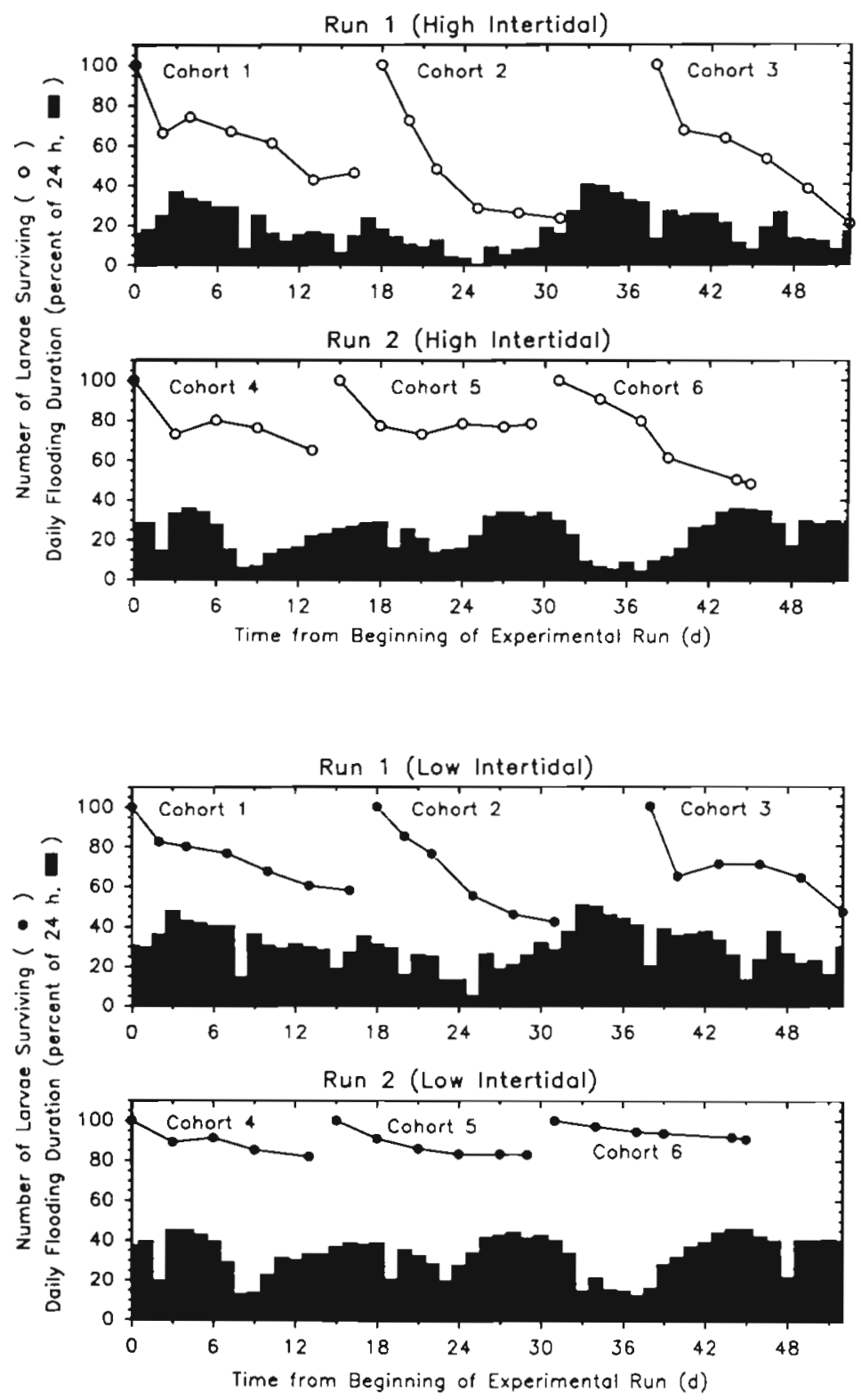

Fig. 4. Fundulus heteroclitus. Survivorship curves for each of the 6 cohorts of larvae reared in field enclosures under the 0-prior cohort. treatment are shown above the tidal flooding regime experienced by each cohort at both high and low intertidal sites

In general, growth and survival were higher at the low elevation, but in comparisons at similar flooding durations (i.e. 5 to $6 \mathrm{~h}$ of flooding), growth rates seemed to be higher and mortality rates lower at the high intertidal elevation (Fig 3). This observation was supported in part by the results of an analysis of covariance (ANCOVA) in which mean growth and mortality rates of the 6 cohorts were compared between elevations after controlling for the covariate (i.e. duration of tidal flooding). There were no significant $(F$-test, $\mathrm{p}>$ 0.05 ) departures from the assumption of variance homogeneity in the ANCOVA analyses. Slopes were not significantly different between elevations for either growth (ANCOVA- $F, \mathrm{p}=0.19$ ) or mortality (ANCOVA- $F, \mathrm{p}=0.43$ ) rate. When adjusted for the flooding duration covariate, the mean growth rate at the high intertidal elevation was significantly greater (ANCOVA- $F, p=$ $0.019)$ than at the low elevation. However, there was no difference between elevations in adjusted mean mortality rates (ANCOVA$F, \mathrm{p}=0.12$ ).

\section{Effects of prior cohorts}

Use of the nursery habitat by prior cohorts of larvae had no detectable direct effect on the mean growth rates within later cohorts, but did affect mortality rate and the total mass of larvae (expressed as change in cohort mass) that could be maintained in each enclosure (Table 5). As in the previous analysis of the 0-prior cohort treatments, spatial (elevation) and temporal (run) variability had strong effects on the response variables. The only significant interaction term in these analyses occurred in the response of growth rate to elevation and run because the difference in growth rates between elevations was greater in Rur 2 than in Run 1 (Fig. 5). Although there seemed to be a tendency for growth rates to be lower in enclosures that had contained prior cohorts in Run 2 at the low intertidal elevation (Fig. 4), there was no significant 3-way interaction (Table 5).

The presence of prior cohorts magnified the pattern of cohort responses to spatial and temporal variability in the nursery environment. Fewer larvae survived in enclosures that had received prior cohorts than in those that had not (Fig 5). The rate of change in cohort biomass combined the responses of growth and mortality rates and reflected the carrying capacity of the nursery environment (in terms of larval biomass per $1.5 \mathrm{~m}^{2}$ enclosure) under each experimental treatment combination. A value near zero meant that the total dry mass of surviving larvae was no greater than the total dry mass of the 100 hatchlings initially stocked into the enclosures $2 \mathrm{wk}$ earlier. The daily change in cohort biomass was either near zero or negative for all treatments in Run 1 but was positive for all treatments in Run 2 (Fig. 4). Use of the nursery habitat by prior cohorts had a negative effect on cohort biomass at both elevations and in both 
Table 5. Fundulus heteroclitus. Summary results of 3-way ANOVA comparing the effects of habitat use by prior cohorts, intertidal elevation and experimental run on average daily specific rates of individual growth, mortality and cohort growth of larvae after 13 to $14 \mathrm{~d}$ in field enclosures. Data from the 1 - and 2-prior cohort treatment levels were pooled

\begin{tabular}{|c|c|c|c|c|}
\hline Source of variation & $\mathrm{df}$ & $\begin{array}{l}\text { Individual growth rate } \\
\qquad\left(\mathrm{mg} \mathrm{mg}^{-1} \mathrm{~d}^{-1}\right)\end{array}$ & $\begin{array}{l}\text { Mortality rate } \\
\qquad\left(Z \mathrm{~d}^{-1}\right)\end{array}$ & 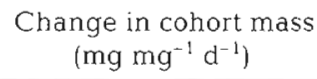 \\
\hline \multicolumn{5}{|l|}{ Main effects } \\
\hline Prior cohorts & 1 & NS & $\cdot$ & $\cdot$ \\
\hline Intertidal elevation & 1 & $\cdots$ & $\cdots$ & $\cdots$ \\
\hline Run & 1 & $\cdots$ & $\cdots$ & $\cdots$ \\
\hline \multicolumn{5}{|l|}{ Interactions } \\
\hline Prior cohorts $\times$ Elevation & 1 & NS & NS & NS \\
\hline Prior cohorts $\times$ Run & 1 & NS & NS & NS \\
\hline Elevation $\times$ Run & 1 & $\cdot$ & NS & NS \\
\hline Prior cohorts $\times$ Elevation $\times$ Run & 1 & NS & NS & NS \\
\hline Residual & 51 & & & \\
\hline
\end{tabular}

experimental runs. Total biomass of larvae was always lower in enclosures at the high than at the low intertidal site.

\section{DISCUSSION}

\section{Variation in growth and mortality among and within cohorts}

Growth and mortality rates within experimental cohorts of Fundulus heteroclitus larvae (Table 3) were lower than those reported for other species in similar field enclosure experiments. For example, Cowan \& Houde (1990) observed mean daily specific growth and mortality rates of 0.20 and 0.15 , respectively for bay anchovy Anchoa mitchilli larvae held in mesocosms suspended on a floating platform in Chesapeake Bay. Growth rates of capelin Mallotus villosus larvae reared in enclosures at ambient conditions in the Gulf of St. Lawrence were similar to those estimated for natural populations (Frank \& Leggett 1986). The highest mean growth rate in the present study ( $G=0.143)$ was less than estimated field growth rates (Kneib 1987) and only half that of $F$. heteroclitus larvae reared in the laboratory on an unrestricted ration (Kneib \& Parker 1991).

The low growth rates observed in the experimental cohorts may have been due to several factors. Studies of marine fish larvae in field enclosures have sometimes detected the effects of cage artifacts that usually occur because the environment within the enclosure does not accurately reflect natural conditions. Fine-mesh walls very quickly can become clogged by the growth of algae or sedentary structure-building animals (de Lafontaine \& Leggett 1987, Cowan \&
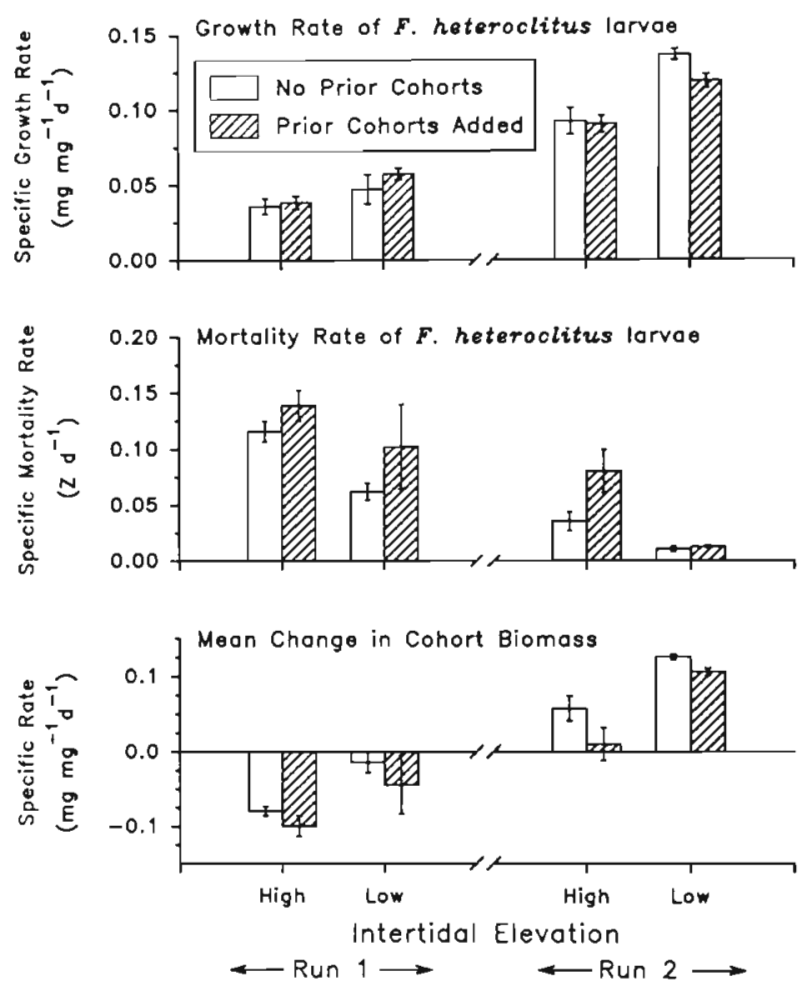

Fig. 5. Fundulus heteroclitus. Responses of larvae (mean \pm $\mathrm{SD})$ to use of the nursery by prior cohorts at high and low intertidal elevations during each experimental run

Houde 1990\}. Fouling of enclosure walls rarely occurs in the intertidal marsh (Bell 1980, Kneib \& Stiven 1982) and was not a problem in this study. Few organisms could tolerate the extreme fluctuations in moisture conditions, which range from complete inundation at high tide to thorough drying between tides. The small amounts of algae, sediments and detrital particles that collected on the mesh were 
removed by the grazing activities of common marsh periwinkles Littoraria irrorata. Also, the large size of Fundulus heteroclitus larvae permitted the use of a relatively large mesh size $(0.5 \mathrm{~mm})$ for the enclosure walls and although prey densities were not monitored, copepods and other small prey organisms should have been able to move freely into and out of the experimental plots during flood tides. Most other enclosure artifacts have resulted from placing physical structures (i.e. cages) in a normally structure-poor environment, altering currents, trapping or eroding sediments, or affecting the behavior of the organisms in the enclosures (Dayton \& Oliver 1980, de Lafontaine \& Leggett 1987, Gamble \& Fuiman 1987, Fuiman \& Gamble 1989). The emergent vegetation of the intertidal marsh provides a large measure of natural structure that seems to buffer the effects of any reasonable addition of artificial structure. Finally, because $F$. heteroclitus larvae normally are confined to shallow aquatic microhabitats on the marsh surface, it was unlikely that their behavior was seriously altered by the presence of the enclosures.

Stocking density of larvae in the field experiments (100 larvae per enclosure or ca 17 larvae per aquatic microhabitat) was well within the range of natural densities at which Fundulus heteroclitus larvae were found in the intertidal nursery. During semimonthly maxima in larval abundance, determined by reproductive periodicity in the adult population (Kneib 1986a), the mean number of larvae collected from artificial aquatic microhabitats (10 cm diameter petri dish) in an unenclosed $300 \mathrm{~m}^{2}$ sampling grid at the low intertidal elevation ranged from 2.9 to $182(n=10)$. When averaged over 11 cohorts that were sampled at the site in 1989 , the mean number of larvae per microhabitat was 32 (author's unpubl. data). However, unlike natural cohorts of $F$. heteroclitus larvae, in which usually fewer than $5 \%$ survived for $3 \mathrm{~d}$ after hatching (author's unpubl. data), mortality within the experimental cohorts was low and 20 to $90 \%$ of the larvae survived for $2 \mathrm{wk}$ in the enclosures. The high survival of larvae in this experiment was probably due to the exclusion of predators because mortality rates of fish larvae in enclosure experiments often are very sensitive to the presence or absence of predators (Øiestad 1982, Frank \& Leggett 1986, Cowan \& Houde 1990). Because of the low mortality in enclosed cohorts, the larvae in this experiment probably were maintained at densities higher than those experienced in the natural population, even though initial stocking density was low relative to many natural peaks in hatchling density.

In the absence of predators, what controlled growth and mortality rates within the cohorts of Fundulus heteroclitus larvae? Differences in the performance of cohorts between runs was not caused by general insta- bility in the physical environment early in the season compared to the later stable environmental conditions because not all of the cohorts in Run 1 performed poorly relative to those in Run 2. Also, most of the factors contributing to environmental variability (i.e. temperature, salinity, day length) should have had the same effect within cohorts at each intertidal elevation, but this was not the case as indicated by the significant Cohort $\times$ Elevation interaction terms in the ANOVA results (Table 2 ). The only measured physical factor associated with variation in growth and mortality rates of fish larvae on both temporal and spatial scales was duration of tidal inundation (Table 4, Fig. 4). I believe this factor influenced growth and mortality in the experimental cohorts of $F$. heteroclitus larvae by affecting prey availability.

Marine and estuarine nursery habitats are usually viewed as productive environments where food concentrations do not limit growth of larval and juvenile fishes (e.g. Currin et al. 1984, Purcell \& Grover 1990 , van der Veer et al. 1990). However, this general conclusion is primarily based on observational studies, which often do not consider either nutritional quality or availability in estimates of food supply and include only individuals that survive and are available for capture. Several physical factors may influence the local availability of food in the nursery, producing spatial and/or temporal variability in the growth and survival among different cohorts of larvae and hence their contribution to annual recruitment of the species. For example, high mortality within larval cohorts of anadromous American shad Alosa sapidissima in the Connecticut River was associated with storms and accompanying periods of high river runoff, which increased turbidity and presumably reduced prey capture efficiency of the sight-feeding larvae (Crecco \& Savoy 1987. Savoy \& Crecco 1988).

Food availability in this experiment likely was influenced by the tidal regime, a predictably variable feature in the physical environment of this nursery habitat (Fig. 2). Young Fundulus heteroclitus had unrestricted access to prey, principally benthic harpacticoid copepods (Kneib 1986b), only when the intertidal nursery was flooded by the tide, which was on average 28 to $32 \%$ and 16 to $22 \%$ of any given $24 \mathrm{~h}$ period at the low and high intertidal sites, respectively. However, most of the time ( 68 to $84 \%$ of each $24 \mathrm{~h}$ period), the intertidal nursery was not flooded and fish larvae were confined to aquatic microhabitats (i.e. shallow pools and puddles of residual tidal water) on the marsh surface. In laboratory experiments, $F$. heteroclitus larvae that were offered an unrestricted ration each consumed an average of 100 to 163 copepod-size prey (Artemia sp. nauplii) $\mathrm{d}^{-1}$ at a post-hatch age of $1 \mathrm{~d}$, and 251 to 371 prey $\mathrm{d}^{-1}$ at $3 \mathrm{~d}$ post-hatch (Kneib \& Parker 1991). At 
these prey consumption rates and given that natural and experimental cohorts of larvae were confined most of the time to shallow aquatic microhabitats, the local depletion of food resources within these microhabitats would not be surprising. Reduced copepod densities have been observed in sediments associated with the microhabitats in which $F$. heteroclitus larvae normally reside, such as the residual tidal water that collects around fiddler crab Uca pugnax burrows (Bell et al. 1978). Prey populations depleted in aquatic microhabitats at low tide could be recolonized by copepods and other potential prey on subsequent flood tides because large numbers of benthic copepods are redistributed on the intertidal marsh surface during each tidal cycle (Palmer \& Brandt 1981). Renewal of prey population densities is probably more rapid in low intertidal habitats, which are flooded more frequently and for longer periods than high intertidal sites. This hypothesis of prey dynamics in the intertidal nursery is consistent with the generally higher growth rates and lower mortality rates observed in cohorts of fish larvae held at the low compared to the high intertidal site (Table 3 , Fig. 3).

Duration of tidal inundation, though clearly associated with cohort responses in this experiment, did not completely explain the differences in growth between groups of fish larvae held at low and high intertidal elevations. When growth rates were adjusted for differences in duration of tidal inundation between sites, fish larvae grew faster at the high than at the low intertidal site (Fig. 3). Copepods are less abundant at high than low intertidal marsh habitats (Bell 1979, Coull et al. 1979), so other prey species may be more important in the high intertidal portion of the nursery. A likely alternative prey for young mummichogs in this area of the nursery is the tanaidacean Hargeria rapax, a small ( 1 to $4 \mathrm{~mm}$ ) peracarid crustacean that is much more abundant in the high marsh than in the low marsh (Kneib 1992). Although considerably larger than most copepods, juvenile tanaids frequently occur in the guts of Fundulus heteroclitus larvae and become increasingly important in the diet as the fish grow (Kneib $1986 \mathrm{~b})$. Access to this prey resource would still be restricted by the duration of tidal inundation but greater profitability associated with feeding on the larger prey could compensate for the limitation on foraging time.

\section{Effects of prior cohorts}

Prior use of the nursery habitat by Fundulus heteroclitus larvae reduced survival in subsequent cohorts of larvae (Table 5, Fig. 5), further supporting the contention that food limitation was an important factor in this experiment. The influence of tidal flooding duration was apparent in the significant effects of intertidal elevation and experimental run. The effect of the prior cohort treatment was in addition to and largely uninfluenced by the spatial and temporal effects of tidal flooding duration as indicated by the absence of significant interaction terms involving prior cohorts in the ANOVA (Table 5). The only significant interaction in this analysis occurred because larvae grew faster at the low than at the high intertidal elevation during Run 2, but not during Run 1 (Fig. 5).

Failure of the prior cohort treatment to affect growth rates in subsequent cohorts was surprising and requires some explanation. As noted earlier, mean growth rates of larvae at all levels of the prior cohort treatment were much less than those observed in the laboratory under an unrestricted ration (Kneib \& Parker 1991), suggesting that growth rates in the field enclosures were constrained to the low end of their potential range. This may have reduced the sensitivity of growth rate as a response variable and perhaps masked the effect of the experimental manipulation. An alternative, and perhaps more likely explanation, is that growth rate compensated for mortality. Although undetected by the ANOVA, prior cohorts may have had a negative effect on growth rate when mortality was very low and densities of larvae remained high as in enclosures at the low intertidal during Run 2 (Fig. 5). Results of a $t$-test using data only from the low intertidal site in Run 2 indicated that growth rate was lower in enclosures that had received prior cohorts than those without prior cohorts ( $\mathrm{p}=0.018)$; mean mortality rates in the same enclosures were very low and did not differ ( $t$-test, $\mathrm{p}=0.429$ ).

Variation in the capacity of the intertidal nursery to support Fundulus heteroclitus larvae was demonstrated best by the change in cohort biomass under the different treatment combinations (Fig. 5). In Run 1, the environment was unable to support even the initial stocking biomass of larvae ( 36 to $42 \mathrm{mg} \mathrm{m}^{-2}$ ). Cohort biomass increased during Run 2 as a result of higher growth and lower mortality rates. The low intertidal elevation had a greater capacity than the high intertidal to support standing stocks of fish larvae, most likely because tidal flooding duration was greater at the low site. Under all conditions, use of the habitat by prior cohorts reduced the nursery's capacity to support larvae (Fig. 5). The results demonstrated that the intertidal nursery did not have the capacity to support the number of larvae normally produced by the adult population of $F$. heteroclitus. The findings provide experimental evidence for the hypothesis that production of successive cohorts of larvae by some marine fishes is a mechanism for reducing effects of intraspecific competition by helping to keep the cohorts nutritionally inde- 
pendent (Lambert 1984, Lambert \& Ware 1984). Predators, which were excluded from this experiment, may mitigate the effects of competition within natural cohorts of larvae by maintaining larval densities below the carrying capacity of the intertidal nursery.

The reproductive pattern of Fundulus heteroclitus, which produces multiple cohorts of larvae over a prolonged spawning season (Taylor et al. 1979, Kneib 1986a), is consistent with theoretical expectations for a reproductive strategy that effectively diffuses mortality risk for the young in a fluctuating environment (Schaffer 1974, Stearns 1977). This type of reproductive pattern, which primarily occurs among marine fishes with demersal eggs, has been considered a 'bet-hedging' strategy that ensures at least some cohorts will experience conditions favorable for survival and growth (Lambert \& Ware 1984, Sherman et al. 1984). Another feature in the reproductive cycle of $F$. heteroclitus resembles a pattern observed in some pelagic spawners, which may have evolved an 'all-at-once' strategy that depends on matching the production of a single large cohort of eggs with a predictable period of high food abundance for the young (Cushing 1975, Ware 1977). Reproductive activity in $F$. heteroclitus is synchronized with periods in the tidal cycle (i.e. spring tides) that may maximize the availability of intertidal prey resources for each cohort of larvae. The reproductive pattern of $F$. heteroclitus seems to combine features from the 'bet-hedging' and 'all-at-once' reproductive strategies exhibited by other species (Lambert \& Ware 1984) and may be one mechanism by which mummichogs maintain large and stable populations (Valiela et al. 1977. Meredith \& Lotrich 1979) in the fluctuating estuarine environment.

Acknowledgements. The successful completion of this work was due in large measure to the stalwart assistance of $F$. Anderson, J. Parker and S. Somerlot, all of whom participated in constructing field enclosures as well as monitoring and maintaining the experimental treatments. A. E. Stiven provided comments and suggestions that improved on an earlier draft of this paper. Financial support was provided by the National Science Foundation under grant number OCE8715449. This paper is Contribution No. 720 of the University of Georgia Marine Institute.

\section{LITERATURE CITED}

Able, K. W. (1984). Variation in spawning site selection of the mummichog, Fundulus heteroclitus. Copeia 1984: $522-525$

Allen, D. M., Barker, D. L. (1990). Interannual variations in larval fish recruitment to estuarine epibenthic habitats. Mar. Ecol. Prog. Ser. 63: 113-125

Bauer, R. T. (1989). Continuous reproduction and episodic recruitment in nine shrimp species inhabiting a tropical seagrass meadow. J. exp. mar. Biol. Ecol. 127: $175-187$
Bell, S. S. (1979). Short- and long-term variation in a high marsh meiofauna community. Estuar. coast. mar. Sci. 9: $331-350$

Bell, S. S. (1980). Meiofauna-macrofauna interactions in a high salt marsh habitat. Ecol. Monogr. 50: 487-505

Bell, S. S., Watzin, M. C., Coull, B. C. (1978). Biogenic structure and its effect on the spatial heterogeneity of meiofauna in a salt marsh. J. exp. mar. Biol. Ecol. 35: 99-107

Boehlert, G. W., Mundy, B. C. (1988). Roles of behavioral and physical factors in larval and juvenile fish recruitment to estuarine nursery areas. Am. Fish. Soc. Symp. 3: 51-67

Boesch, D. F. Turner, R. E. (1984). Dependence of fishery species on salt marshes: the role of food and refuge. Estuaries $7(4 \mathrm{~A}): 460-468$

Chao, L. N., Musick, J. A. (1977). Life history, feeding habits and functional morphology of juvenile sciaenid fishes in the York River estuary, Virginia. Fish. Bull. U.S. 75: $657-702$

Coull, B. C., Bell, S. S., Savory, M., Dudley, B. W. (1979). Zonation of meiobenthic copepods in a southeastern United States salt marsh. Estuar. coast. mar. Sci. 9: $181-188$

Cowan, J. H. Jr, Houde, E. D. (1990). Growth and survival of bay anchovy Anchoa mitchilli larvae in mesocosm enclosures. Mar. Ecol. Prog. Ser. 68: 47-57

Crecco, V., Savoy, T. (1987). Effects of climatic and densitydependent factors on intra-annual mortality of larval American shad. Am. Fish. Soc. Symp. 2: 69-81

Currin, B. M., Reed, J. P., Miller, J. M. (1984). Growth, production, food consumption, and mortality of juvenile spot and croaker: a comparison of tidal and nontidal nursery area. Estuaries 7(4A): 451-459

Cushing, D. H. (1975). Marine ecology and fisheries. Cambridge University Press, Cambridge

Dayton, P. K., Oliver, J. S. (1980). An evaluation of experimental analyses of population and community patterns in benthic marine environments. In: Tenore, K. R., Coull, B. C. (eds.) Marine benthic dynamics. University of South Carolina Press, Columbia, p. 93-120

de Lafontaine, Y., Leggett, W. C. (1987). Evaluation of in situ enclosures for larval fish studies. Can. J. Fish. Aquat. Sci. 44: $54-65$

DiMichele, L., Taylor, M. H. (1980). The environmental control of hatching in Fundulus heteroclitus. J, exp. Zool. 214: $181-187$

Frank, K. T., Leggett, W. C. (1982). Environmental regulation of growth rate, efficiency, and swimming performance in larval capelin (Mallotus villosus), and its application to the match/mismatch hypothesis. Can. J. Fish. Aquat. Sci. 39: $691-699$

Frank, K. T., Leggett, W. C. (1986). Effect of prey abundance and size on the growth and survival of larval fish: an experimental study employing large volume enclosures. Mar. Ecol. Prog. Ser. 34: 11-22

Fuiman, L. A., Gamble, J. C. (1989). Influence of experimental manipulations on predation of herring larvae by juvenile herring in large enclosures. Rapp. P.-v. Réun. Cons. int. Explor. Mer 191: 359-365

Gamble, J. C., Fuiman, L. A. (1987). Evaluation of in situ enclosures during a study of the importance of starvation to the vulnerability of herring larvae to a piscine predator. J. exp. Mar. Biol Ecol. 113: 91-103

Gamble, J. C., MacLachlan, P., Seaton, D. D. (1985). Comparative growth and development of autumn and spring spawned Atlantic herring larvae reared in large enclosed ecosystems. Mar. Ecol. Prog. Ser. 26: 19-33 
Grant, G. C., Olney, J. E. (1990). Distribution of striped bass Morone saxatilis (Walbaum) eggs and larvae in major Virginia rivers. Fish. Bull. U.S. 89: 187-193

Heck, K. L. Jr, Thoman, T. A. (1984). The nursery role of seagrass meadows in the upper and lower reaches of the Chesapeake Bay. Estuaries 7: 70-92

Kneib, R. T. (1984). Patterns in the utilization of the intertidal salt marsh by larvae and juveniles of Fundulus heteroclitus (Linnaeus) and Fundulus luciae (Baird). J. exp. mar. Biol. Ecol. 83: 41-51

Kneib, R. T. (1986a). Size-specific patterns in the reproductive cycle of the killifish, Fundulus heteroclitus (Pisces: Fundulidae) from Sapelo Island, Georgia. Copeia 1986: $342-351$

Kneib, R. T. (1986b). The role of Fundulus heteroclitus in salt marsh trophic dynamics. Am. Zool. 26: 259-269

Kneib, R. T. (1987). Predation risk and use of intertidal habitats by young fishes and shrimp. Ecology 68: 379-386

Kneib, R. T. (1992). Population dynamics of the tanaid Hargeria rapax (Crustacea: Peracarida) in a tidal marsh. Mar. Biol. 113: 437-445

Kneib, R. T., Parker, J. H. (1991). Gross conversion efficiencies of mummichog and spotfin killifish larvae from a Georgia salt marsh. Trans. Am. Fish. Soc. 120: 803-809

Kneib, R. T., Stiven, A. E. (1982). Benthic invertebrate responses to size and density manipulations of the common mummichog. Fundulus heteroclitus, in an intertidal salt marsh. Ecology 63: 1518-1532

Lambert, T. C. (1984), Larval cohort succession in herring (Clupea harengus) and capelin (Mallotus villosus). Can. J. Fish. Aquat. Sci. 41: 1552-1564

Lambert, T. C., Ware, D. M. (1984). Reproductive strategies of demersal and pelagic spawning fish. Can. J. Fish. Aquat. Sci. 41: 1565-1569

Leak, J. C., Houde, E. D. (1987). Cohort growth and survival of bay anchovy Anchoa mitchilli larvae in Biscayne Bay, Florida. Mar. Ecol. Prog. Ser. 37: 109-122

Lipcius, R. N., Subrahmanyam, C. B. (1986). Temporal factors influencing killifish abundance and recruitment in Gulf of Mexico salt marshes. Estuar. coast. Shelf Sci. 22: $101-114$

Little, K. T., Epifanio, C. E. (1991). Mechanims for the re-invasion of an estuary by two species of brachyuran megalopae. Mar. Ecol. Prog. Ser. 68: 235-242

Livingston, R. J., Kobylinski, G. J., Lewis, F. G. III, Sheridan, P. F. (1976). Long-term fluctuations of epibenthic fish and invertebrate populations in Apalachicola Bay, Florida. Fish. Bull. U.S. 74: 311-321

MacKenzie, B. R., Leggett, W. C. (1991). Quantifying the contribution of small-scale turbulence to the encounter rates between larval fish and their zooplankton prey: effects of wind and tide. Mar. Ecol. Prog. Ser. 73: 149-160

McBride, R. S., Conover, D. O. (1991). Recruitment of youngof-the-year bluefish Pomatomus saltatrix to the New York Bight: variation in abundance and growth of spring- and summer-spawned cohorts. Mar. Ecol. Prog. Ser. 78: 205-216

Meredith, W. H., Lotrich, V. A. (1979). Production dynamics of a tidal creek population of Fundulus heteroclitus (Linnaeus). Estuar. coast. mar. Sci. 8: 99-118

Norcross, B. L., Shaw, R. F. (1984). Oceanic and estuarine transport of fish eggs and larvae: a review. Trans. Am. Fish. Soc. 113: 153-165
Norusis, M. J. (1990). SPSS/PC+ Statistics 4.0 for the IBM $\mathrm{PC} / \mathrm{XT} / \mathrm{AT}$ and PS/2. [Subprogram of the Statistical Package for the Social Sciences]. SPSS, Inc., Chicago

Øiestad, V. (1982). Application of enclosures to studies on the early life history of fishes. In: Grice, G. D., Reeve, M. R. (eds.) Marine mesocosms, biological and chemical research in experimental systems. Springer-Verlag. New York, p. 49-62

Palmer, M. A., Brandt, R. R. (1981). Tidal variation in sediment densities of marine benthic copepods. Mar Ecol. Prog. Ser. 4: 207-212

Purcell, J. E., Grover, J. J. (1990). Predation and food limitation as causes of mortality in larval herring at a spawning ground in British Columbia. Mar. Ecol. Prog. Ser. 59: $55-61$

Rogers, S. G., Targett, T. E., Van Sant, S. B. (1984). Fishnursery use in Georgia salt-marsh estuaries: the influence of springtime freshwater conditions. Trans. Am. Fish. Soc. 113: 595-606

Savoy, T. F., Crecco, V. A. (1988). The timing and significance of density-dependent and density-independent mortality of American shad, Alosa sapidissima. Fish. Bull. U.S. 86: $467-482$

Schaffer, W. M. (1974). Optimal reproductive effort in fluctuating environments. Am. Nat. 108: 783-790

Shaw, R. F., Rogers, B. D., Cowan, J. H. Jr, Herke, W. H. (1988). Ocean-estuary coupling of ichthyoplankton and nekton in the northern Gulf of Mexico. Am. Fish. Soc. Symp. 3: 77-89

Sherman, K., Smith, W., Morse, W., Berman, M., Green, J., Ejsymont, L. (1984). Spawning strategies of fishes in relation to circulation, phytoplankton production, and pulses in zooplankton off the northeastern United States. Mar. Ecol. Prog. Ser. 18: 1-19

Sokal, R. R., Rohlf, F. J. (1981). Biometry. W.H. Freeman and Company, San Francisco

Stearns, S. C. (1977). The evolution of life history traits: a critique of the theory and a review of the data. A. Rev. Ecol. Syst. 8: 145-171

Taylor, M. H., DiMichele, L., Leach, G. J. (1977). Egg stranding in the life cycle of the mummichog, Fundulus heteroclitus. Copeia 1977: 397-399

Taylor, M. H., Leach, G. J., DiMichele, L., Levitan, W. M., Jacob, W. F. (1979). Lunar spawning cycle in the mummichog, Fundulus heteroclitus (Pisces: Cyprinodontidae). Copeia 1979: 291-297

Valiela, I., Wright, J. E., Teal, J. M., Volkmann, S. B. (1977). Growth, production and energy transformations in the salt-marsh killifish, Fundulus heteroclitus. Mar. Biol. 40: $135-144$

van der Veer, H. W., Pihl, L., Bergman, M. J. N. (1990). Recruitment mechanisms in North Sea plaice Pleuronectes platessa. Mar. Ecol. Prog. Ser. 64: 1-12

Ware, D. M. (1977). Spawning time and egg size of Atlantic mackerel, Scomber scombrus, in relation to the plankton. J. Fish. Res. Bd Can. 34: 2308-2315

Weinstein, M. P. (1979). Shallow marsh habitats as primary nurseries for fishes and shellfish, Cape Fear River, North Carolina. Fish. Bull. U.S. 77: 339-357

Zastrow, C. E., Houde, E. D., Morin, L. G. (1991). Spawning, fecundity, hatch-date frequency and young-of-the-year growth of bay anchovy Anchoa mitchilli in mid-Chesapeake Bay. Mar. Ecol. Prog. Ser. 73: 161-171

Manuscript first received: September 18, 1992

Revised version accepted: February 8, 1993 